\title{
Modeling the Budgetary Impact of Payer Utilization Management Strategies: An Adapted Framework Based on Lessons Learned
}

\author{
Anna Hung, PharmD, PhD, MS; Amy Lugo, PharmD; and C. Daniel Mullins, PhD
}

\begin{abstract}
SUMMARY
Historically, budget impact models have been used to demonstrate how a new drug or technology entering the market could influence payer budgets, with the hope of influencing coverage of the drug or technology. This article proposes the adaptation of a budget impact model framework to answer the payer question "What is the budget impact of our approaches to managing the utilization of drugs and technologies?" Throughout this article, we also describe lessons learned while collaborating with a U.S. payer to evaluate the budgetary impact of specific antidiabetic drug utilization management approaches.
\end{abstract}

J Manag Care Spec Pharm. 2019;25(8):922-26

Copyright $\odot 2019$, Academy of Managed Care Pharmacy. All rights reserved.

$\mathrm{T}$ raditionally, budget impact models predict the financial impact of a newly approved drug in the market and are provided to payers to help them evaluate how coverage of such a new drug will influence their budget. We now propose an adapted framework that payers can use to generate their own budget impact models.

When a new drug or technology enters the market, payers have varying approaches to manage utilization of the drug or technology. These approaches include formulary coverage and tiers, step therapy, prior authorization criteria, quantity limits, clinical management programs, preferred and exclusive networks, and more. ${ }^{1}$ In addition to market entry, these approaches may change for a variety of reasons, including new evidence, product discontinuation, and changes in pricing, contracting, or policies.

In this new framework, the research question shifts from "What is the budget impact of a new drug or technology entering the market?" to "What is the budget impact of our payer approach to managing drug or technology utilization?" The new research question extends beyond the market entry of a single drug or technology to 1 or many payer "interventions," or approaches to managing utilization. If the payer utilization management (UM) policies of interest affect more than 1 therapeutic area, a budget impact model in the new framework will expand the focus beyond a single therapeutic area to all affected therapeutic areas. Recent examples of health care organization and payer interest in using a budget impact model framework to assess the financial consequences of their programs, formularies, and UM policies indicate growing interest in this area., ${ }^{2,3}$

Although the research question, approach, and sensitivity analyses change in the new budget impact model framework, the concepts and the 6 steps used to teach the original framework for the budget impact model can still be applied. According to the 2014 International Society for Pharmacoeconomics and Outcomes Research (ISPOR) Task Force report on principles of good practice for budget impact analysis (BIA), the following aspects should be considered in the design of a BIA4:

- Features of the health care system

- Perspective

- Use and cost of current and new interventions

o Eligible population

o Current interventions

o Uptake of new intervention and market effects

o Off-label uses of the new intervention

o Cost of the current or new intervention mix

- Impact on other costs

o Condition-related costs

o Indirect costs

- Time horizon

- Time dependences and discounting

- Choice of computing framework

- Uncertainty and scenario analysis

- Validation

Our recent payer-academic collaboration assessed the budgetary impact of formulary and UM policy changes for antidiabetic drugs using actual payer data. ${ }^{3}$ The following sections are lessons learned from this process, embedded into an adapted version of the 6-step framework used by the International Society for Pharmacoeconomics and Outcomes Research (ISPOR) to teach budget impact modeling. ${ }^{5}$ Table 1 compares considerations when modeling the budgetary impact of payer UM policies (adapted framework) with considerations when modeling the budgetary impact of new technologies entering the market (traditional framework).

\section{The 6-Step Framework: Lessons Learned}

\section{Step 1. Characterize Eligible Population}

The eligible population depends on the perspective chosen. Given a payer perspective and said payer's claims data, a starting point for the eligible population is the members who in the year before the UM policy of interest were using drugs or technologies affected by the UM policy. One key advantage to having payer claims data is being able to accurately estimate the size of the population, as well as any relevant subgroup populations. 


\begin{tabular}{|c|c|c|}
\hline Topic & $\begin{array}{l}\text { What to consider when modeling the budgetary impact of new } \\
\text { technologies entering the market (Traditional Framework) }{ }^{4}\end{array}$ & $\begin{array}{l}\text { What to consider when modeling the budgetary impact of } \\
\text { payer UM policies (Adapted Framework) }\end{array}$ \\
\hline $\begin{array}{l}\text { Evaluates impact } \\
\text { of... }\end{array}$ & New drug or technology. & Payer "interventions" or approaches to managing utilization. \\
\hline \multicolumn{3}{|c|}{ Step 1. Characterize Eligible Population } \\
\hline & $\begin{array}{l}\text { Begin by estimating the number covered by the locally approved } \\
\text { indications for the new technology. }\end{array}$ & $\begin{array}{l}\text { Payer claims data provide an accurate initial estimate of the } \\
\text { number of members using the technologies affected by the payer } \\
\text { interventions. }\end{array}$ \\
\hline & $\begin{array}{l}\text { Base on whether the new intervention increases time on } \\
\text { treatment, slows disease progression, or reduces mortality } \\
\text { without curing the condition. }\end{array}$ & $\begin{array}{l}\text { Past historical claims data help inform whether the population } \\
\text { size and disease severity mix should be assumed to be constant } \\
\text { after the payer intervention. }\end{array}$ \\
\hline \multicolumn{3}{|c|}{ Step 2. Select Time Horizon } \\
\hline & $\begin{array}{l}\text { One to five years is common, with the results presented for each } \\
\text { budget period after the new intervention is covered. }\end{array}$ & One to two years with annual estimates may be sufficient. \\
\hline \multicolumn{3}{|c|}{ Step 3. Determine Intervention Mix and Use } \\
\hline & BIA compares scenarios with sets of interventions. & $\begin{array}{l}\text { Evaluation of a step therapy change may require inclusion of more } \\
\text { unique drugs and NDC numbers than what is typically seen for } \\
\text { BIAs evaluating new technologies. }\end{array}$ \\
\hline & $\begin{array}{l}\text { Interventions used off-label in the eligible population may be } \\
\text { included and should not be seen as promotion of off-label use. } \\
\text { However, for the new intervention, since there will be little } \\
\text { effectiveness or safety data on such off-label use and promotion } \\
\text { of off-label use should be avoided, inclusion in the BIA is not } \\
\text { recommended unless the budget holder specifically requests its } \\
\text { inclusion. }\end{array}$ & $\begin{array}{l}\text { Past claims data provide a baseline estimate of all use, including } \\
\text { off-label use of a technology, if the technology was previously } \\
\text { available. If the technology was not available, look to similar } \\
\text { scenarios (e.g., same drug class or similar situation for a similar } \\
\text { disease state) for a range of estimates. }\end{array}$ \\
\hline & & $\begin{array}{l}\text { When predicting utilization changes due to payer intervention } \\
\text { for base case and sensitivity analyses, consider the disease } \\
\text { state, entry and withdrawal of drugs or technologies, new } \\
\text { evidence, provider loyalty to individual interventions, differences } \\
\text { in effectiveness, dosing, types of evidence among drugs or } \\
\text { technologies, and implementation delays. }\end{array}$ \\
\hline & & $\begin{array}{l}\text { When predicting utilization changes due to payer intervention } \\
\text { for base case and sensitivity analyses, consider other payer policy } \\
\text { changes. }\end{array}$ \\
\hline & & $\begin{array}{l}\text { Make the budget impact model flexible to changes in the } \\
\text { availability of drugs or technologies, disease state, evidence, } \\
\text { guidelines, clinician preference in treatment, and policy changes. }\end{array}$ \\
\hline \multicolumn{3}{|c|}{ Step 4. Estimate Intervention Costs } \\
\hline & $\begin{array}{l}\text { The cost of the current or new intervention mix is determined by } \\
\text { multiplying the budget holder's price for each intervention by the } \\
\text { proportion of the eligible population using that intervention and } \\
\text { by the number of people in the eligible population. }\end{array}$ & $\begin{array}{l}\text { Payer cost data allow for more accurate budget impact estimates. } \\
\text { Models should include details important to payers, such as } \\
\text { dispensing fees, other health insurance, plan types, and points } \\
\text { of service. When in doubt regarding assumptions, payers prefer } \\
\text { underestimating the savings. }\end{array}$ \\
\hline \multicolumn{3}{|c|}{ Step 5. Estimate Changes in Condition-Related Costs } \\
\hline & $\begin{array}{l}\text { Provide intervention and condition-related costs separately, } \\
\text { so the end user can see results with and without condition- } \\
\text { related costs. }\end{array}$ & $\begin{array}{l}\text { Agree with original guidance. } \\
\text { Provide pharmacy and medical costs separately, if appropriate for } \\
\text { payer. }\end{array}$ \\
\hline \multicolumn{3}{|c|}{ Step 6. Present Budget Impacts and Health Outcomes } \\
\hline & & Present results for subgroups relevant to the payer. \\
\hline \multicolumn{3}{|c|}{ Time dependencies and discounting } \\
\hline & $\begin{array}{l}\text { Forecasting changes, such as value of currency, uptake, new } \\
\text { interventions entering mix, changes in price, and changes } \\
\text { in understanding of disease, indications, and management } \\
\text { practices, over time can be challenging. However, an attempt } \\
\text { should be made for the study time horizon as long as the } \\
\text { assumptions are clear, justified, and supported by evidence as } \\
\text { feasible. } \\
\text { No discounting. }\end{array}$ & Agree with original guidance. \\
\hline
\end{tabular}




\section{TABLE 1 Differences When Modeling the Budgetary Impact of New Technologies Entering the Market} (Traditional Framework) Versus Payer UM Strategies (Adapted Framework) (continued)

\begin{tabular}{|c|c|c|}
\hline Topic & $\begin{array}{l}\text { What to consider when modeling the budgetary impact of new } \\
\text { technologies entering the market (Traditional Framework) }\end{array}$ & $\begin{array}{l}\text { What to consider when modeling the budgetary impact of } \\
\text { payer UM policies (Adapted Framework) }\end{array}$ \\
\hline \multicolumn{3}{|c|}{ Choice of computing framework } \\
\hline & $\begin{array}{l}\text { Cost calculator approach is the preferred option because it is } \\
\text { more easily understood by budget holders. }\end{array}$ & Agree with original guidance. \\
\hline \multicolumn{3}{|c|}{ Uncertainty and scenario analyses } \\
\hline & $\begin{array}{l}\text { Evaluate parameter uncertainty (input values) and structural } \\
\text { uncertainty (assumptions in framing BIA). One-way sensitivity } \\
\text { analyses and scenario analyses should be performed. } \\
\text { Probabilistic sensitivity analyses are not recommended. }\end{array}$ & Agree with original guidance. \\
\hline \multicolumn{3}{|c|}{ Validation } \\
\hline & $\begin{array}{l}\text { 1. Face validity. } \\
\text { 2. Internal verification. } \\
\text { 3. Where possible, the observed costs in a health plan with the } \\
\text { current interventions should be compared with the initial-year } \\
\text { estimates. }\end{array}$ & $\begin{array}{l}\text { Agree with original guidance. } \\
\text { More emphasis should be placed on validating budget impact } \\
\text { models. }\end{array}$ \\
\hline
\end{tabular}

Next, one should consider whether the size or disease severity mix of the eligible population should change in the model over time. Past historical claims data can help inform this decision. Disease severity may be difficult to determine based on claims data alone; however, where possible, one can create proxy indicators based on the use of medications reserved for later stages of disease, hospitalizations related to the therapeutic area, and more. When electronic medical records are available, determining disease severity may be more easily attainable; however, sometimes the electronic medical records are not available for the entire population of interest.

\section{Step 2. Select Time Horizon}

The time horizon is based on payer preference and time periods relevant to the decision-making process. Often, annual estimates of budget impact are provided, and ISPOR guidelines note that 1-5 years is common. ${ }^{4}$ In our case, we found that only 1-2 years was relevant before the formulary and UM policy changes of interest became obsolete for the decision maker. We also found a shorter time horizon to be more reasonable, considering that the antidiabetic drug landscape quickly changed with new drugs, patent expirations, new evidence, and updated guidelines.

\section{Step 3. Determine Intervention Mix and Use}

Traditionally, the intervention mix includes all relevant drugs or technologies for which utilization could be affected by the market entry of a new drug or technology. ${ }^{4}$ Some UM policy changes can affect numerous drugs and technologies. In our case, a step therapy change required the inclusion of 8 drug classes, with 73 unique drugs and approximately 150 unique National Drug Code (NDC) numbers in our intervention mix.
Given that NDC prices can vary greatly for a given drug, it is important that the intervention mix incorporate NDC number mix, as well as drug mix, based on payer utilization data.

Use of payer claims data is also advantageous because all utilization is revealed, accounting for issues of adherence and persistence, as well as off-label use. This avoids the legal uncertainty that manufacturers face when considering inclusion of off-label use in economic modeling. ${ }^{6,7}$ For a new drug that has not launched, the payer will not have an estimate of off-label use but can sometimes extrapolate from drugs in the same class or estimate a range based on similar scenarios in other clinical areas.

Utilization will change depending on specific payer UM policies of interest. In our study, step therapy changes were expected to decrease the use of drug classes further along in step therapy requirements. Preferred agent policies were expected to increase the use of preferred agents and decrease the use of nonpreferred agents.

How payer UM policies affect use will also depend on the disease state, treatment options, new evidence, and prescribing behavior. In our case, new drug classes, such as the sodium glucose co-transporter-2 inhibitors (SGLT2Is), and individual drugs, such as semaglutide, dulaglutide, lixisenatide, ertugliflozin, and such combinations as insulin degludec/liraglutide and insulin glargine/lixisenatide have emerged for diabetes. Just as new drugs and drug classes became available, discontinuations were announced, and drugs were expected to go off patent. For example, Tanzeum (albiglutide) was expected to be no longer made as of July 2018. ${ }^{8}$ The patent for Byetta (exenatide) expired in 2017, yet no generics have been approved to date. ${ }^{9}$ In addition, several cardiovascular outcomes trials have shown favorable outcomes for some of the newer agents. ${ }^{10,11}$ 
With new drug classes and new evidence, clinical guidelines have also been changing. All of these aspects can affect how payer UM policies will affect utilization. Because of the many rapid changes, it would be ideal to make the model flexible to include and exclude various drugs and adapt to changes in understanding of disease state, treatment options, evidence, guidelines, and clinician preference.

In our case, one of the drug classes of interest, the SGLT2Is, was a newer class of oral diabetes medications. This class was expected to be less complicated because of fewer drugs and very similar dosing and administration between the agents, allowing for a large market shift from nonpreferred agents to preferred agents. In contrast, the glucagon-like peptide-1 receptor agonists (GLP1RAs) have been in existence longer than the SGLT2Is, and clinicians have loyalty to certain agents.

There are also differences in dosing regimen (twice daily vs. once daily vs. once weekly), differences in duration of action and effect on fasting or postprandial glucose, and perceived differences in glycemic control and weight loss for GLP1RAs. All of these factors can affect provider and patient preference for one drug versus another within the same drug class. Thus, drug classes with different characteristics and varying provider/ patient preferences affect how effective a UM policy will be.

Furthermore, providers employed by an integrated delivery system may follow UM policies more strictly compared with independent providers. Thus, payers should use their experience in understanding their providers' prescribing patterns and health care delivery systems to more accurately estimate utilization changes after their UM policies of interest are implemented. Specifically, in our case, we expected higher switch rates from nonpreferred to preferred agents within the SGLT2I drug class compared with the GLPIRA drug class.

One should also remember that in the real world, implementation of payer UM policies may be delayed. In our case, implementation of formulary and UM policy changes occurred later than expected, and our budget impact model included a scenario to mimic this implementation delay.

Beyond the payer UM policies of interest, one must also consider other relevant changes in broader payer policies. For example, use of the drugs of interest were not only affected by the step therapy and preferred agent policy changes, but also by copay increases and changes in preferred pharmacy networks. An advantage of working with payers is understanding other internal policies that could affect the success of the payer UM policy of interest.

Sensitivity analyses should include estimates from payers regarding the extent to which their population and prescribers will abide by payer UM policies, given the aforementioned considerations. These estimates should be informed by historical data where possible and, if not available, based on expert opinion from the payer. Sensitivity analyses can also incorporate scenarios such as implementation delays or other payer policy changes.

\section{Step 4. Estimate Intervention Costs}

A common problem with current budget impact models is estimation of drug costs. Often these costs are proprietary and therefore unknown. Having payer data allows for an internal budget impact model to be built with true cost estimates, after rebates. Nonetheless, publications of the budget impact model will often require substitution with publicly available cost estimates.

When measuring costs, models should include details that are relevant to payers. For example, members can have other health insurance, and depending on the type of insurance, payers may not pay as much for these members' care. This should be reflected in the budget impact model. Other relevant details include dispensing fees, plan types, and points of service.

When in doubt, payers prefer conservative estimates in budget impact savings. A sensitivity analysis is very helpful in understanding the "what-ifs."

\section{Step 5. Estimate Changes in Condition-Related Costs}

Traditionally, condition-related costs include the costs for medical resource use affected by the new drug or technology. These costs will also vary based on the perspective chosen, and even the commonly used payer perspective may lead to the inclusion of different costs based on the specific type of payer. For example, a Medicare Part D plan may want to consider the drug costs alone, while a Medicare Advantage plan that is responsible for medical and pharmacy benefits may want to consider medical visit costs and drug costs.

However, regardless of payer type, ISPOR guidelines suggest that condition-related costs be included in the model, but with the flexibility that would allow the end user of the model to see results with and without these costs. Ideally, we agree with these guidelines; however, we acknowledge that, practically, a Medicare Part D plan with limited time and resources that is developing its own budget impact model may choose to omit condition-related costs. In our case, the payer we collaborated with was mostly concerned about impact on the pharmacy benefit (i.e., the medical benefit was separate from the pharmacy benefit). Thus, we provided separate budget impact estimates on the pharmacy and medical benefits. Many health plans continue to have challenges coordinating care and costs between the medical and pharmacy benefit; ultimately, however, models should accommodate the end user's situation.

\section{Step 6. Present Budget Impacts and Health Outcomes}

Budget impacts and health outcomes should be presented for time periods and subgroups relevant to the payer. Total cost and per member per month figures are often provided as measures of budget impact. Measures of health outcomes, along with what is considered a meaningful change in health outcome, will depend on the therapeutic area and what payer data are available (e.g., claims and/or electronic medical records). Annual 


\section{Modeling the Budgetary Impact of Payer Utilization Management Strategies: \\ An Adapted Framework Based on Lessons Learned}

time periods and subgroups related to pharmacy points of service were of highest interest to the payer in our study.

\section{Other Considerations}

We agree with the ISPOR BIA guidelines regarding time dependencies and no discounting, choice in computing framework, uncertainty and scenario analyses, and validation (see Table 1). While validation is briefly mentioned in the ISPOR BIA guidelines, we have rarely seen validation in practice. For payers to use budget impact models, we believe the gap in validation is an area that needs to be addressed.

Overall, we learned many lessons in collaborating with a payer to apply the ISPOR BIA guidelines to predict the effect of a payer intervention. We hope these lessons, as well as the adapted framework, are helpful for future research.

\section{Authors}

ANNA HUNG, PharmD, PhD, MS, Duke Clinical Research Institute, Durham, North Carolina; AMY LUGO, PharmD, Defense Health Agency, San Antonio, Texas; and C. DANIEL MULLINS, $\mathrm{PhD}$, University of Maryland School of Pharmacy, Baltimore.

AUTHOR CORRESPONDENCE: Anna Hung, PharmD, PhD, MS, Duke Clinical Research Institute, 200 Morris St., Durham, NC 27701. Tel.: 919.668.1493; E-mail: anna.hung@duke.edu

\section{DISCLOSURES}

The study discussed in this commentary was supported by grant number F32HS024857 from the Agency for Healthcare Research and Quality (AHRQ). The content is solely the responsibility of the authors and does not necessarily represent the official views of AHRQ, which had no role in the design and conduct of the study; collection, management, analysis, and interpretation of the data; preparation, review, or approval of the manuscript; or design to submit the manuscript for publication. The findings discussed in this manuscript represent the views of the authors and do not necessarily reflect the views of the Department of Defense, the Defense Health Agency, nor the Departments of the Army, Navy, and Air Force.
Hung reports personal fees from CVS Health and BlueCross BlueShield Association, outside the submitted work. Lugo has nothing to disclose. Mullins reports grants and other fees from AHRQ, during the conduct of the study; grants and personal fees from Bayer and Pfizer; and personal fees from Boehringer-Ingelheim, Janssen/J\&J, Regeneron, and Sanofi, outside the submitted work.

Parts of the study were presented as a poster presentation at the 2017 AMCP Managed Care \& Specialty Pharmacy Annual Meeting; March 27-30, 2017; Denver, CO, and as poster and oral presentations at the 2017 AMCP Nexus Meeting; October 16-19, 2017; Dallas, TX. The study was also published as Hung's PhD dissertation.

\section{REFERENCES}

1. Shoemaker SJ, Dengelis J. An annotated bibliography of managed care pharmacy interventions. Academy of Managed Care Pharmacy. January 15, 2010. Available at: http://www.amcp.org/WorkArea/DownloadAsset. aspx?id=9276. Accessed May 31, 2019.

2. Ni W, Colayco D, Hashimoto J, et al. Budget impact analysis of a pharmacist-provided transition of care program. J Manag Care Spec Pharm. 2018;24(2):90-96. Available at: https://www.jmcp.org/doi/10.18553/ jmcp.2018.24.2.90.

3. Hung A, Mullins CD, Slejko, JF, Haines ST, Shaya F, Lugo A. Using a budget impact model framework to evaluate antidiabetic formulary changes and utilization management tools. J Manag Care Spec Pharm. 2019;25(3):342-49. Available at: https://www.jmcp.org/doi/10.18553/jmcp.2019.25.3.342.

4. Sullivan SD, Mauskopf JA, Augustovski F, et al. Budget impact analysisprinciples of good practice: report of the ISPOR 2012 Budget Impact Analysis Good Practice II Task Force. Value Health. 2014;17(1):5-14.

5. ISPOR Short Course Program. Budget impact analysis I : a 6-step approach. 2016.

6. Perfetto EM, Burke L, Oehrlein EM, Gaballah M. FDAMA Section 114: Why the renewed interest? J Manag Care Spec Pharm. 2015;21(5):368-74 Available at: https://www.jmcp.org/doi/10.18553/jmcp.2015.21.5.368.

7. Neumann PJ, Saret CJ. When does FDAMA Section 114 apply? Ten case studies. Value Health. 2015;18(5):682-89.

8. Military Health System Communications Office. Drugmaker discontinuing type 2 diabetes medication. June 8, 2018. Available at: https://health. mil/News/Articles/2018/06/08/Drugmaker-discontinuing-Type-2-diabetesmedication. Accessed June 7, 2019.

9. Sagonowsky E. AstraZeneca, Teva settle Byetta patent suit; generics on their way. FiercePharma. June 24, 2016. Available at: https://www.fiercepharma.com/pharma/astrazeneca-teva-settle-byetta-patent-suit-generics-theirway. Accessed May 31, 2019.

10. Zinman B, Wanner C, Lachin JM, et al. Empagliflozin, cardiovascular outcomes, and mortality in type 2 diabetes. N Engl J Med. 2015;373(22):2117-28.

11. Marso SP, Daniels GH, Brown-Frandsen K, et al. Liraglutide and cardiovascular outcomes in type 2 diabetes. N Engl J Med. 2016;375(4):311-22. 